\title{
AN INFANTILISM OF THE INTELLECTUALLY AND SPIRITUALLY MATURED PERSONALITY: SOARING AND PRECIPICE
}

\author{
Vadim S. Rotenberg* \\ Tel-Aviv University, Bat-Yam, Israel \\ Received December 19, 2009; accepted January 23, 2009
}

\begin{abstract}
The target problem of this article paradoxically dropped out from the vision of professional psychologists although it is actual and even acute. The consideration of this problem is important not only for the practical psychotherapy, but also for the deep and, let us say, philosophical comprehension of the fundamental aspects of personal maturation and of the difference between genders in the process of maturation.
\end{abstract}

Key words: Psychotherapy; Personal maturation; Self-Image

\section{INTRODUCTION}

The target problem of this article paradoxically dropped out from the vision of professional psychologists although it is actual and even acute. The consideration of this problem is important not only for the practical psychotherapy, but also for the deep and, let us say, philosophical comprehension of the fundamental aspects of personal maturation and of the difference between genders in the process of maturation. Of course, this problem is relevant for both boys and girls, however, particularly for girls it often becomes especially important and sometimes even converts into tragedy. For this reason, I will start the presentation with problems of girls.

These girls are serious and thoughtful and usually make a good impression. They are well educated and display broad interests in cultural and spiritual life. They are able to think seriously about general ethical and humanitarian problems that do not touch their coevals. Usually they are listening to their interlocutors with high attention and a strong intention to understand what they are speaking about. They are often attractive for boys and men standing out from the routine circle. They irradiate a charm mystery based on their rich inner world.

And at the same time they are very unlucky and this becomes obvious very soon after they start a new relationship. A new person who is already interested and fascinated by such a girl suddenly finds that she seems to be unreasonably lost in the process of relationships especially when it is necessary to feel a state and mood of the partner and to behave according to this feeling - it means, to feel it and to behave spontaneously, without logical analysis, on the intuitive level, like it usually happens in the process of natural interpersonal communications. This unexplained confusion makes an impression that this outstanding girl is in a state of tension, feels not self-confident and self-efficient, but diffident and unhappy.

Her suddenly manifested helplessness as a sign of deep complexes she is suffering from is in an obvious contrast to her charm and spirituality. It looks like a fear to create deep interpersonal relationships, and it is a correct feeling. I am not speaking about sexual relationships in its pure form because these relationships in our culture became very functional and often very superficial, not including real intimate and deep emotional connections. I am speaking exactly about close intimate relationships on the personal level that includes a feeling and understanding of the partner as a person, as well as feeling herself in these relationships.

The central figure of the novel "The Precipice" of the Russian classical writer I.G. Goncharov displays such a girl. She lives in her inner world of vague day-dreams and imaginations, in high spiritual rushes and a little bit haughtily ignores the routine interests and the ordinary life of her relatives. She looks very attractive and mysterious in her day-dreams and intentions, and one delicate, spiritual and artistic man falls in non-mutual love with her. This love is not mutual seemingly just because this man was in harmony with himself and with the world, and she was searching for somebody who looks extraordinary and is ready to challenge the "routine"

*Correspondence to: Vadim Rotenberg, email: vadir@post.tau.ac.il 
values. As a result she finally became a victim of an empty narcissistic person with a provoking behavior. Inspiration and animation with day-dreams is replaced in these girls by confusion and frustration just when their dreams have to turn into real personal interrelationships. As a result a girl is going to avoid the development of these relationships and cuts them rapidly causing a hard despair for the man who already fell in love with her.

\section{CASE}

One of my clients was a beautiful young woman 25 years old, charming, attentive and serious - a combination of features that made her absolutely irresistible. Her romantic relationships with men developed according to the same scenario every time: a partner fell in love with her, her initial reaction was positive, she was sure that she loved him too. Suddenly when the relationship became more and more close and it was time to be together in a more direct way, she got an impression that she did not want it, that she is already tired with him, - and she stopped the relationships without any definite explanations. The partner became confused and frustrated. In a short period my client asked herself with surprise what the reason to stop her relationships was, she made an intention to restore them, the partner reacted on this intention in a very enthusiastic way. However very soon she stopped it once more. She suffered from guilt, confusion and depression, she even started to hate herself, but was unable either to change nor to explain her behavior, although in other conditions, not related to intimate interconnections she was usually able to search for and to find reasonable explanations of her actions.

It is possible to suggest that the main reason of the frustration of these girls is the dissociation between the insufficient maturation of their personality contrasted with an outstanding high intellectual and spiritual maturation. Their ability to understand and to solve different intellectual problems, their reflexivity and spiritual needs and their education are high. But the personal maturation is something different. Intelligence determines the ability to perform a logical analysis of causeand effect relationships and to make a correct probability forecast in structured conditions. In the process of spiritual maturation a subject's basic values and highest needs are formed, particularly ethical values and general interests that go behind the pragmatic tasks and goals. In contrast, personal maturity includes the harmonic integration into the complicated system of polydimensional and polysemantic interpersonal relationships, particularly emotional relationships. Such relations are too many-sided to be exhaustively analyzed and interpreted. They have to be understood not on the conceptual level but to be grasped on the level of holistic intuitive feelings. Analytical approach makes them impoverished.

\section{EMOTIONAL RELATIONSHIPS AND BRAIN MECHANISMS}

For the relevant perception of interpersonal emotional relationships a subject needs special brain mechanisms located in the right frontal lobe. This part of the brain passes a long process of development and definitively matures later than other brain zones (Saugstad, 1998). It is known that the longer is the process of maturation and the later the structure achieves its full maturity the higher and more complicated is its function. Actually, the right frontal lobe is responsible for the highest human functions: creativity (Tucker et al., 1999), metaphorical way of thinking (Anaki et al., 1998; Winner, Gardner, 1977), theory of mind (understanding how a subject is understood by other people, Platek et al., 2004), sense of humor (Wapner et al., 1981), empathy (Shamai-Tsoori et al., 2003), formation of the polysemantic Self-Image strongly related to and integrated in the polydimensional world that is full of formal contradictions Craik et al., 1999, Keenan et al., 2000; 2001; Rotenberg, 2007). All these functions achieve their highest stage of development after the formation of the logical analytical thinking which is a function of the left frontal lobe. The analytical way of thinking, behind all its abovementioned advantages, simplifies the reality, splits it in peaces (for analysis), and as a result destroys its holistic feature. In addition, being equipped only with the analytical way of thinking, a person finds himself to be separated from the world (see Rotenberg, 2007).

After its maturation the right frontal lobe compensates this by-product of the left-hemispheric logical thinking and brings back a feeling of integration in the holistic world - a feeling that is typical for the happy childhood before the maturation of the left frontal lobe. Of course in the matured person this feeling is restored on another level and includes all advantages of the logical - analytical way of thinking (Rotenberg, 2007).

The maturation of the right frontal lobe and the formation of the Self-Image depend on the experience of various interpersonal (first of all emotional) relationships that important others (family members, friends, etc) are building with the child. For the normal personal maturity a child has to be understood and accepted by its parents on all steps of his/her development. Interest of parents and their empathy is the main condition that allows children to apply to parents with any problems, without a risk to frighten them, to cause tension and to be rejected. However, children and adolescents with an extraordinary high intellectual and spiritual need that even may exceed the corresponding needs of parents have a high chance to become isolated in their own family and to be rejected by parents who cannot understand them and are afraid of their inability to understand their own children. Even if the relationships in this condition are not broken, they are less efficient. Without regular 
warm collaboration with parents, without orientation on their spiritual and personal experience that child is loosing a mirror that he/she needs for personal maturation. Self-Image is the holistic self- perception of the subject in all relationships with the world (with nature, with other people and with the culture). It is an intuitive selfidentity that allows a subject without any conscious arguments to suggest with a confidence "Here I am, and this is suitable (or not suitable) for me". The formed and integrative Self-Image reflects the matured personality that is aware (not necessary on the conscious level) about a subject's own goals and values the subject is ready to pay for.

For the topic of this article it is necessary to emphasize that girls in general are characterized by the earlier maturation of the brain, both left and right hemisphere (Heller, 1993; Saugstad, 1998). In men the final maturation of the right frontal lobe is achieved with a long delay in comparison to women (see Rotenberg, 2004). It is worth to mention that the brain structure that is passing a longer period of normal development achieves a higher functional ability after final maturation. It can explain the higher creative efficacy of men in comparison to women. However, an earlier personal maturation gives a subject some advantages in the process of interpersonal communications. Girls at the same age are more "adult" than boys - it is a common place. For this reason the society also expects girls to be more matured as persons, to be oriented in more subtle and flexible way in interpersonal emotional relationships and to be more sensitive to these relationships. Actually this expectation of the society corresponds to the social role of women as a key figure in the emotional atmosphere in the family and in the process of bringing up children , especially in early stages. The harmony of the personal and intellectual maturation of the woman (girl) displays itself, in particular, not only in the more subtle feeling of the interpersonal relationships but also in understanding that man according to his nature is less sensitive to these relationships and may be clumsy in his reactions. The matured women ( girl) has not to be offended by this clumsiness and does not expect from the man the same sensitivity as she herself displays. The relations with the opposite gender are usually more important for women than for men.

There are different options in the relationships between the intellectual and personal maturation. If the process of personal maturation of the girl is going with some delay in comparison to the social expectations, and her intellectual and spiritual level is also not very high, girl is not suffering and is not disappointed with herself, it does not cause frustration. The behavior of such girl is infantile, however, she does not realize it and she accepts the requirements of the society in the same infantile way. They can cause only a superficial and terminal childish feeling of being "offended" without reasons.
This girl does not understand what other people are awaiting from her (according to her age and gender), she does not feel guilt, and the reaction of the society in such case becomes also relatively condescending: "what can we await from this child?" Such a girl does not cause any illusions in men. Her maturation is going slowly and without dramatic events, and she finally achieves a normal level of personal maturation (or it does not happen at all and in this case it will become a problem of a man who falls in love with such an infantile woman). If the interpersonal relationships do not satisfy such a girl on the step of the delayed maturity, she draws a conclusion like "they do not like me", "they do not understand me", "they are bad". She blames the outside world in order to avoid frustration.

In contrast, the personal immaturity of the intellectual and spiritual girl is associated with the agonizing feeling of her own guilt for being unable to create harmonic relationships and at the same time for the inability to understand what is going wrong and why. This girl is unable to understand what is going on because the task is not an intellectual one: the obstacle - her personal immaturity - has to be grasped on the intuitive level, but intuition comes together with maturation of the right frontal lobe. Intellectual and spiritual maturation increases the expectations and demands towards the girl herself and causes a confusion and despair due to the inability to correspond to these demands without a clear understanding why. However, the dissatisfaction is realized and often is accompanied by a feeling of helplessness. Girls are more sensitive to their personal immaturity than boys because in most cases their selfidentification is less based on the pure intellectual interests and achievements in outward oriented activity, they feel that they have to understand something more in interpersonal relationships, but what?...

Due to the high spiritual and intellectual level, due to the broad circle of interests these girls feel like being in a free inspired flight. And suddenly this flight, this soaring is crushed.

It happens sometimes that these girls display an unconscious intention to fall in love with a person who is much older and seems to be matured and responsible. This actually is a search for a protective father - especially if this girl had no such father in her childhood. Near such a "father" she becomes relaxed, she feels that such person can understand her. Sometimes such intention may cause problems if the adult friend gets an illusion and accept this search for a protector as a real love (I remind that these girls are often very attractive).

However, there is also another group of girls with a dissociation between intellectual and personal maturation, nevertheless they are not suffering and are not frustrated. For these girls interpersonal relationships are not important, they are oriented exclusively on spiritual life and intellectual achievements that totally determine 
their self-identification. It is a masculine type of personal development. They are not sensitive to their personal infantilism, as if it doesn't matter, and they can stay in this infantile position for a long period. In this case not they but those men who fall in love with them suffer.

Lu Salome, one of the central figures of the spiritual life in Europe at the end of the 19 century belonged to this type of girls (see Livingstone, 1984). She was really very creative in mental activity and very attractive. Nitzshe, Rilke and many other outstanding men became victims of her inability to react like a woman in interpersonal relationships. She avoided sex up to being 30 years old. She tried to turn the attempts to involve her in emotional relationships into pure intellectual collaborations. In childhood she was surrounded by brothers and felt herself as an equal partner in their masculine community. She was quite satisfied with her life, and even when she turned to sexual relationships they were also on a very functional level, without emotional closeness. Boys in general have lower requirements to their own level of personal maturation because the world for them is an object of mental activity and they care less about the harmony of personal relationships. The world to them is a challenge, not a source of pleasure, and they often wish to be assertive more than to be loved. As a result, when the emotional contacts between genders are not successful, intellectual but infantile boys start to blame, hate and despise girls, while intellectual infantile girls start to blame themselves.

\section{CONCLUSION}

The abovementioned concept is a key for the psychological treatment of girls who are suffering from the dissociation in intellectual and personal maturation. Psychologist cannot simply accelerate personal maturation. The process of such maturation requires the development of interpersonal relationships. But frustration and confusion prevents such relations and blocks this process.

One of the main reasons of emotional tension and confusion is the incomprehension of the girl's own present state. Actually, a girl is at that moment in a stage of her maturation as a person, and maturation is a process. By estimating her level of intelligence and her spiritual needs she beliefs that she is already adult, that her personality is already formed, that she is matured and consequently all her problems will stay this way forever, they have no chance to disappear. In this state a girl might think that it is the final stage of her development. It is very important to make her free from this illusion in the process of psychotherapy.

My experience shows that girls with these problems accept the idea of their personal immaturity (with all abovementioned explanations) as an insight, with great enthusiasm, because it gives them hope. As soon as they realize themselves in the process of development, not on its final stage they accept all their experiences in a more easy way and it destroys the vicious circle that pressed them to the ground.

It is necessary to help them to feel themselves not as passive objects of this process of maturation but as active subjects and to explain that the maturation of the corresponding brain structures is not going by itself according to the biological laws but strongly depends on the increasing experience of emotional relationships with people. Even the unavoidable mistakes and failures in the process of such relationships are natural and helpful and it is not necessary to be afraid of them.

If the deficit of such experience was in their early youth as a result of their isolation from the family, it is also necessary to consider that in the process of psychotherapy. It is reasonable to show that parents often have no guilt - they were simply afraid to form connections due to their inability to understand their children, as was explained before. But it also means that the immaturity can be conquered in the process of the formation of new interpersonal relations with people who are equal to these girls according to their intellectual scale, even if such relationships look difficult at the beginning.

Usually girls become inspired with this explanation and it can change their life.

\section{REFERENCES}

Anaki D., Faust M., \& Kravetz S. (1998). Cerebral hemispheric asymmetries in processing lexical metaphors. Neuropsychologia, 36, 353-362.

Craik F.I.M., Moroz T.M., Moscovitch M., Stuss D.T., Winocur G., Tulving E., \& Kapur S. (1990). In search of the self: a positron emission tomography study. Psychological science, 10, 26-34.

Heller W. (1993). Gender differences in depression: perspectives from neuropsychology. Journal of affective disorders, 29, 129-143.

Platek S., Keenan J., Gallup G.Jr., \& Mohamed F. (2004). Where am I? The neurological correlates of self and other. Cognitive brain research, 19, 114-122.

Keenan J.P., Wheeler M., Gallup G.Jr., \& Pascual-Leone A. (2000). Self-recognition and the right prefrontal cortex. Trends in Cognitive Sciences, 4, 338-344.

Keenan J.P., Nelson A., O'Connor M., \& Pascual-Leone A. (2001). Self-recognition and the right hemisphere. Nature, 409, 305.

Livingstone A. (1984) Salome: Her Life and Work. New York,: Moyer.

Rotenberg V.S. (2004). The peculiarity of the righthemisphere function in depression: solving the paradoxes. Progress in Neuro-Psychopharmacology \& Biological Psychiatry, 28, 1-13.

Rotenberg V.S. (2007). The asymmetry of the frontal lobe functions and the fundamental problems of mental health and psychotherapy. Dynamische Psychiatrie/Dynamic Psychiatry, 219-220, 51-68.

Saugstad L.F. (1998). Cerebral lateralization and rate of maturation. International Journal of Psychophysiology, 28, 3762. 
Shamai-Tsoori S.G., Tomer R., Berger B.D., \& Aharon-Peretz J. (2003). Characterization of empathic deficits following prefrontal brain damage. The role of the right ventromedial prefrontal cortex. Journal of Cognitive Neuroscience, 15, 324337.

Tucker D.M., Hartry-Speiser A., McDougal L., Luu Ph., \& de Grandpre D. (1999). Mood and spatial memory: emotion and right hemisphere contribution to spatial cognition. Biological Psychiatry, 50, 103-125.

Wapner W., Hamby S., \& Gardner H. (1981). The role of the right hemisphere in the apprehension of complex linguistic materials. Brain and language, 14, 15-33.

Winner E., \& Gardner H. (1977). The comprehension of metaphor in brain damaged patients. Brain, 100, 717-729. 